\title{
Analysis on the Pricing of White Sugar Options Under Knight Uncertainty Environment
}

\author{
Hua Deng \\ Department of Mathematics and Finance, Hunan University of Humanities, Science and Technology, Loudi, China \\ Email address: \\ huakate@163.com

\section{To cite this article:} \\ Hua Deng. Analysis on the Pricing of White Sugar Options Under Knight Uncertainty Environment. International Journal of Science and \\ Qualitative Analysis. Vol. 3, No. 6, 2017, pp. 61-65. doi: 10.11648/j.ijsqa.20170306.12
}

Received: December 21, 2017; Accepted: January 16, 2018; Published: February 2, 2018

\begin{abstract}
There is a particular situation in the financial market that the natural state space is known and the probability distribution is unknown which called Knight Uncertainty. The strict assumption of the traditional pricing model in the past was challenged. The influence of Knight Uncertainty on the pricing of financial derivatives white sugar options is discussed. The price of white sugar option in China is empirical analyzed by using the option pricing model under Knight Uncertain environment. The pricing interval of the option is obtained by using the net uncertainty coefficient. At the same time, it is found that the parameters of Knight Uncertainty directly affect the accuracy of pricing through comparison with real price. It can fit well with the real price if taking the appropriate size of the net uncertainty metric parameter. The research results can provide theoretical support for investors and regulators.
\end{abstract}

Keywords: Knight Uncertainty, The White Sugar Option, Option Pricing

\section{Introduction}

Reasonable price of financial derivatives is the premise to promote the healthy and healthy development of the market. It can provide a guarantee for the promotion of market risk management. The Knight Uncertainty in real financial markets is a universal phenomenon on the particularity of the financial market [1]. It can not to be ignored. Knight uncertainty performance objectively reflects the uncertainty characteristics of financial market and helps to reveal the law of asset pricing. It is not only one of the basic features of the market for securities and derivatives, but also the main content of the research on the pricing of risky assets and the behavior of the investors [2]. Many experts at home and abroad have studied the uncertainty of knight in option pricing [3]. In this paper, Knight Uncertainty environment of underlying asset price is the current empirically analysis through the use of Chinese options market data. The feasibility of the model is analyzed and gets the conclusions. The research results have good applicability to the derivatives market. It has a positive effect on the stable development of the securities industry and the banking industry. The way and the model referred in the paper is not only practical value, but also have high theoretic value.

\section{The Option Pricing Model Under Knight Uncertainty}

\subsection{The Pricing Interval Under the Black-Scholes Option Model}

1. The characteristics of the option price

The price of an option is equal to the intrinsic value of the option plus the time value [4].

The intrinsic value of the option is the maximum value of the discounted value of the income obtained when 0 and multiple options are exercised. The multiparty European call option can only be exercised at the expiration of the option, so its intrinsic value is the present value of $\left(S_{T}-X\right)$. For unprofitable assets, the present value of $S_{T}$ is the current market price ( $S$ ). For the assets that pay for cash income, the present value of $S_{T}$ is $S-D$. The present value of the cash income of the assets marked in the option validity period is Therefore, the intrinsic value of the European call option of unyielding assets is equal to $S-X e^{-r(T-t)}$.

The time value of option is the implied value of the underlying asset price fluctuation when the option is not yet 
expired, which is the possibility of the option holder's income. It is clear that the higher the volatility of the underlying asset price, the greater the time value of the option [5].

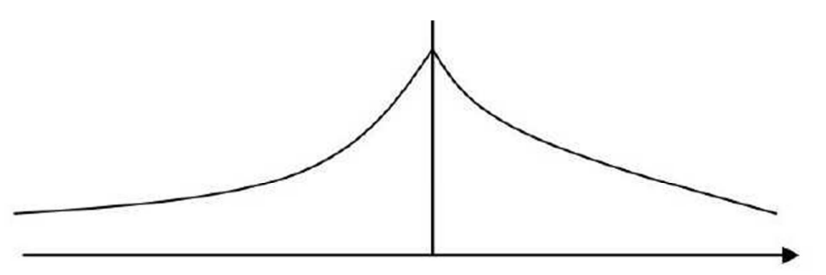

$$
X e^{-r(T-t)}
$$

Figure 1. The relationship between the time value of the call option of unyielding assets and $\left(S-X e^{-r(T-t)}\right)$.

In addition, the time value of the option is also influenced by the intrinsic value of the option. Take the unyielding asset call option as an example. The time value of the option is the greatest when $S=X e^{-r(T-t)}$. When the absolute value of $S-X e^{-r(T-t)}$ increases, the time value of the option is diminishing, as shown in Figure 1.
2. The price ceiling of the European Call Option

There is a chance of arbitrage if the price of a European Call Option exceeds the price of the underlying asset. Arbitrage can get risk free profit by buying the underlying assets and selling options. Therefore the value of an option will not exceed the price of the underlying asset in any case. So for American and European put options, the underlying asset price is the upper limit of the call option price:

$$
C \leq S
$$

Among them, C represents the price of European call option, and $\mathrm{S}$ represents the underlying asset price.

3. The price floor of the European Call Option

In order to deduce the price lower limit of the option, let's assume a European call option for an unyielding asset. Consider the following two combinations [6]:

Combination 1: A European call option and cash of $X e^{-r(T-t)}$

Combination 2: A unit of assets

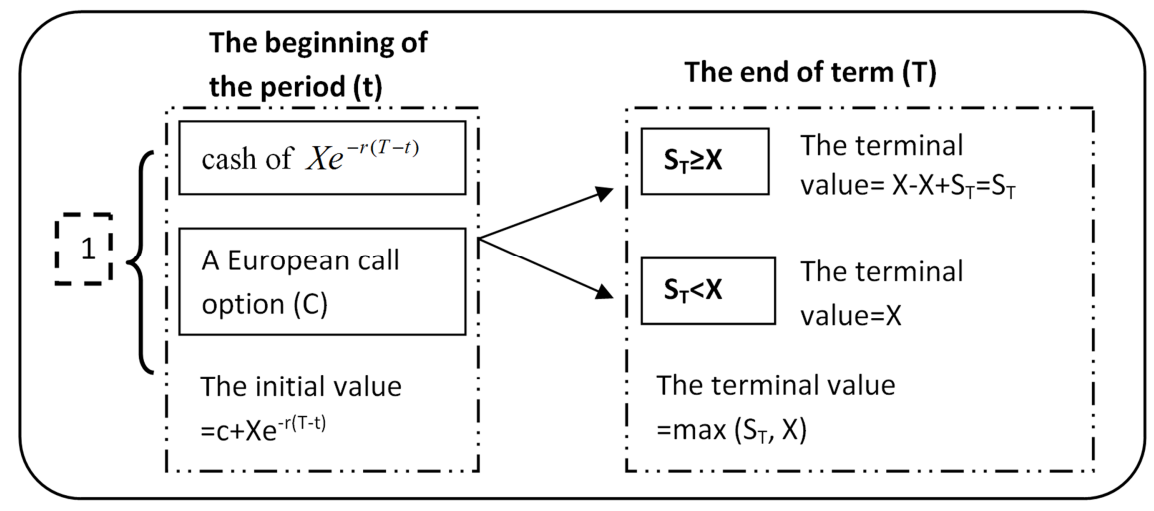

Figure 2. The graphical of value analysis of Combination 1.

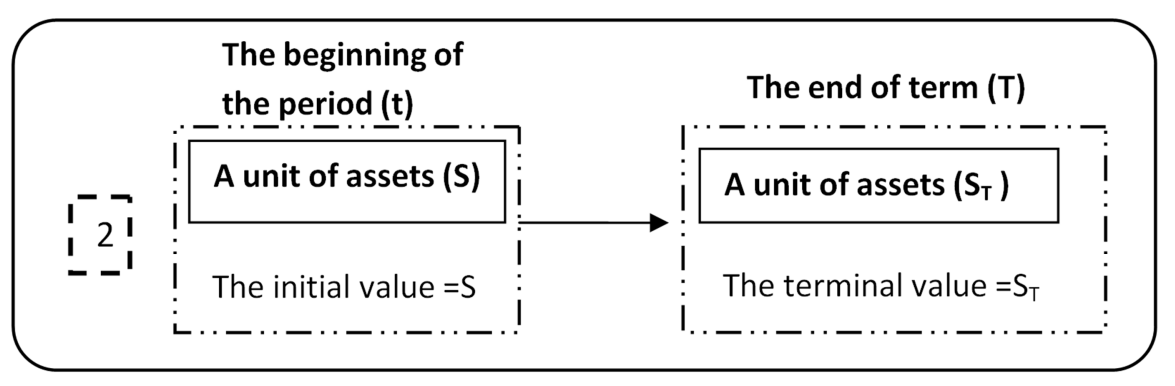

Figure 3. The graphical of value analysis of Combination 2.

In the combination 1 , it will become $X$ if the cash is invested at risk free interest rate at $\mathrm{T}$ time. That is equal to the price of the agreement. At this time, whether the long option position choose to execute the call option depends on whether the asset price $\left(S_{T}\right)$ of the T time scale is greater than $X$. if $S_{T}>X$, Then execute the call option, the value of the combination of $S_{T}$; if $S_{T} \leq X$, The call option is not executed, and the value of the combination of $\mathrm{A}$ is Therefore, in the $\mathrm{T}$ moment, the value of the combination of $\mathrm{A}$ is: $\max \left(S_{T}, X\right)$

And at $\mathrm{T}$ time, the value of combining B is $S_{T}$. owing to $\max \left(S_{T}, X\right) \geq S_{T}$, Therefore, the value of the combination of $A$ at $t$ time should be greater than equal to the combination of $\mathrm{B}$, That is:

$$
C+X e^{-r(T-t)} \geq S
$$

Therefore $C \geq S-X e^{-r(T-t)}$

As the value of the option must be positive, the price lower 
limit of the European call option for unyielding assets is:

$$
\mathrm{C} \geq \max \left[S-X e^{-r(T-t)}, 0\right]
$$

4. The price curve of the European Call Option

From the analysis of the influence factors of the option price and the value of the option, the shape of the option price curve can be preliminarily introduced.

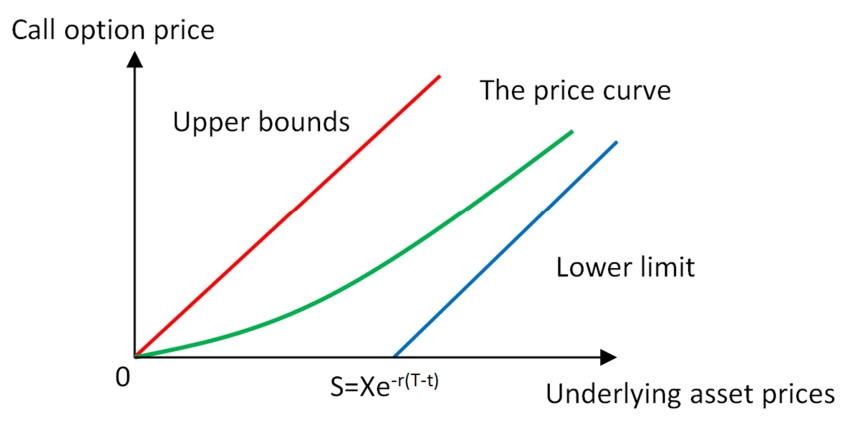

Figure 4. The price curve of the European Call Option.

Because the option price is equal to the intrinsic value plus the time value, the upper limit of the call option price is $\mathrm{S}$, The lower limit is $\max \left[S-X e^{-r(T-t)}, 0\right]$, The lower limit of the right price is the intrinsic value of the option.

The upper and lower limit of this option price has a certain value to the option pricing, but its scope is too large, it is not accurate enough and the error is large. Therefore, in order to derive the exact formula of option pricing, it is necessary to reduce the interval and further study the exact interval of the option price.

\subsection{Option Pricing Model Under Knight Uncertainty}

Uncertainty refers to all other states other than the uncertain risk with probability distribution. It is called nit uncertainty or fuzzy uncertainty [1]. A great deal of research has been made by scholars at home and abroad about the influence of Knight Uncertainty on Asset Pricing [7].

Introducing a set of feasible control sets [8]:

$$
\theta=\left\{\mathrm{Q}^{\theta}\left|\frac{\mathrm{dQ}^{\theta}}{\mathrm{dQ}}\right|_{F_{T}}=\exp \left\{-\int_{0}^{T} \theta_{S} d B_{s}^{Q}-\frac{1}{2} \int_{0}^{T} \theta_{S}^{2} d s\right\}\right\}
$$

Variable $\alpha$ in the measurable centralization is been defined as a hierarchical parameter as the degree of nit uncertainty in the financial market. The minimum and maximum pricing of European options is obtained. That is, the option pricing is not a certain value, but a certain interval under the uncertainty of Knight. The smaller the parameters $\alpha$ means that the uncertainty of Knight in the financial market is weak. $\alpha=0$ means to converge in the traditional sense of risk. On the contrary, the bigger the parameter $\alpha$, the stronger the uncertainty of Knight in the financial market.

Taking the Black-Scholes model [9] as the theoretical basis, the knight parameters was considered in the model.

Proposition: Suppose that all investors are rational, then, the reasonable price of a European call option under Knight
Uncertainty is not a definite value but an interval $\left[C_{\min }, C_{\max }\right][10]$.

The price lower limit of the European call option under the net uncertainty is

$$
C_{\min }=S e^{-\alpha \sigma T} N\left(d_{1}\right)-K e^{-r T} N\left(d_{2}\right)
$$

The price upper limit of the European call option is

$$
C_{\max }=S e^{\frac{\alpha}{1+\alpha} \sigma T} N\left(d_{3}\right)-K e^{-r T} N\left(d_{4}\right)
$$

Among them $S$ representing the price of the underlying asset, $K$ representing the executive price of white sugar options, $r$ is risk free interest rate, $\sigma$ is price volatility. $T$ is the period of options.

At the same time

$$
\begin{gathered}
d_{2}=\frac{\ln \frac{S}{K}+\left(r-\alpha \sigma-\frac{1}{2} \sigma^{2}\right) T}{\sigma \sqrt{T}}, d_{1}=d_{2}+\sigma \sqrt{T}, \\
d_{4}=\frac{\ln \frac{S}{K}+\left(r+\alpha(1+\alpha) \sigma-\frac{1}{2} \sigma^{2}\right) T}{\sigma \sqrt{T}}, d_{3}=d_{4}+\sigma \sqrt{T},
\end{gathered}
$$

$N($.$) is the cumulative probability distribution function for$ the standard normal.

And

$$
N(x)=\int_{-\infty}^{x} \frac{1}{\sqrt{2 \pi}} e^{-\frac{t^{2}}{2}} d t
$$

Therefore, the model can be used to calculate the reasonable pricing of options under Knight Uncertainty.

\section{Empirical Analyses}

\subsection{Selection of Samples}

The empirical sample used in this paper is the white sugar option data of the Zhengzhou Mercantile Exchange from June 26, 2017 to November 24, 2017 (SR801C6000). Its duration is 105 days. The original data came from the Zhengzhou Mercantile Exchange. The data will be mixed with a variety of noise components which directly obtained from the market. It will have a great impact on the modeling calculation. Therefore, it is necessary to screen a series of original data first in data processing. The processed data can be brought into the model to get more accurate conclusions. The principle of data screening is:

First: The maturity of the data should not be too short or too long in order to avoid the possible problems of liquidity. So only keep the date between half a year and 1 year.

Second: the study chose the most effective and latest data for this year.

Third: In order to truly reflect the actual situation, chose the option contract that is prior to this study.

Fourth: In order to ensure the frontier of the research chose the latest product white sugar option which is listed this year. 
Risk free interest rate $r$ selection 2017 Shanghai interbank dismantling interest rate (SHIBOR), 1 year's single interest is $4.6987 \%$, It needs to be converted into a 1 day single interest. Its daily rate of return is

$$
(\sqrt[365]{1+4.6987 \%}-1) \cdot 365=0.05 \%
$$

The rate of volatility is the mean value of the implied volatility of the 105 trading days, That is $14.69 \%$, In order to discuss the relationship between the parameter size of Knight uncertainty and the price range of white sugar option, different parameters was chose to compare and analyze. Namely $\alpha=0, \alpha=1, \alpha=3$, It indicates 3 levels, such as no Knight uncertainty (Traditional Black-Scholes pricing model), weak Knight uncertainty, and a stronger degree of Knight uncertainty, respectively.

\subsection{Data Analysis}

Based on formula (3) and formula (4), the change characteristics of the price of the white call option was obtained in the case of net uncertainty $(\alpha=0)$ by Using MATLAB 7.1 (Figure 5).

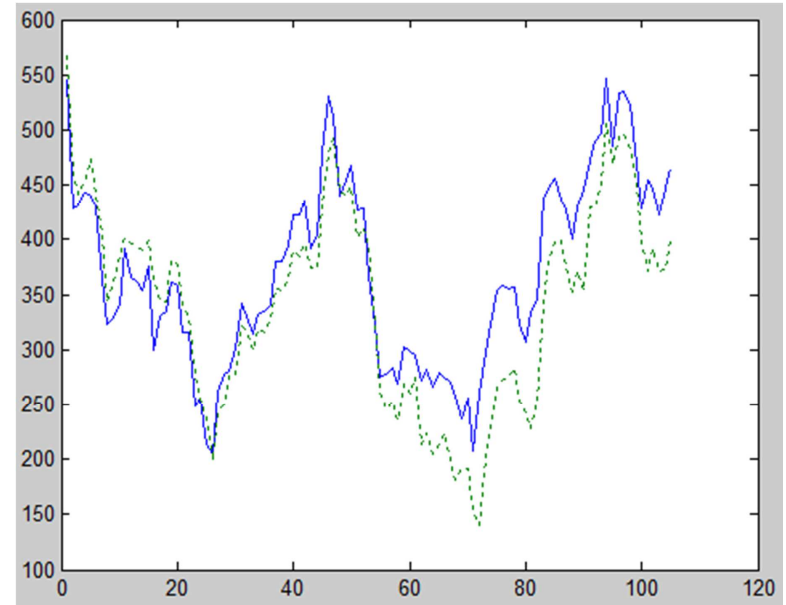

Figure 5. The pricing of white sugar options without Knight Uncertainty $(\alpha=0)$.

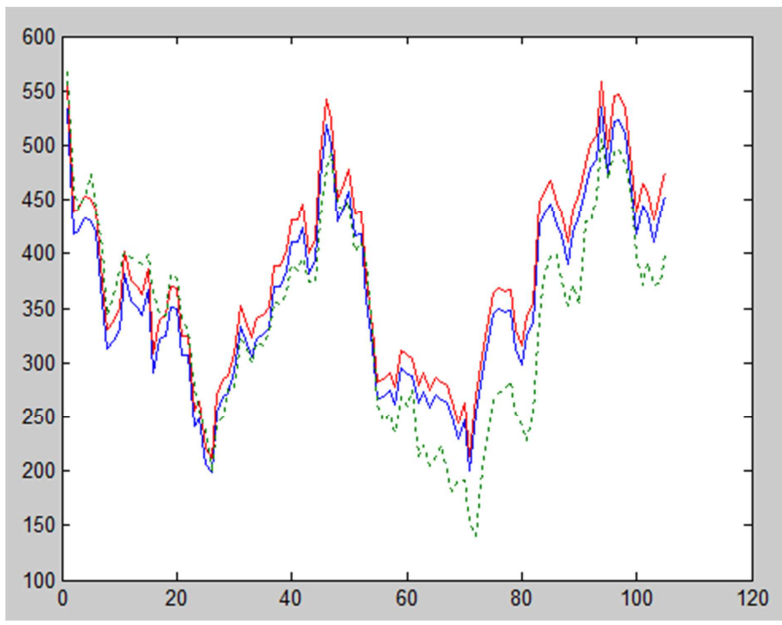

Figure 6. The prediction price range of a white sugar call option under the Knight parameter $\alpha=0.05$.

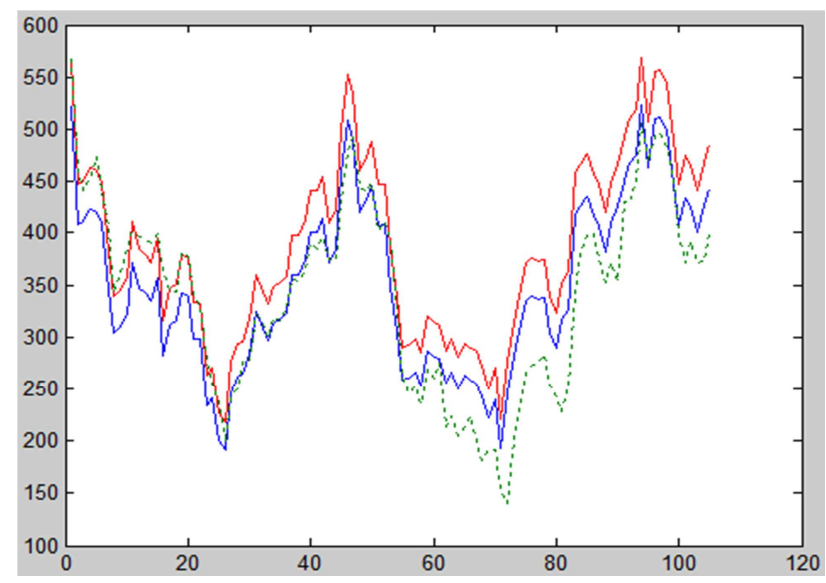

Figure 7. The prediction price range of a white sugar call option under the Knight parameter $\alpha=0.1$.

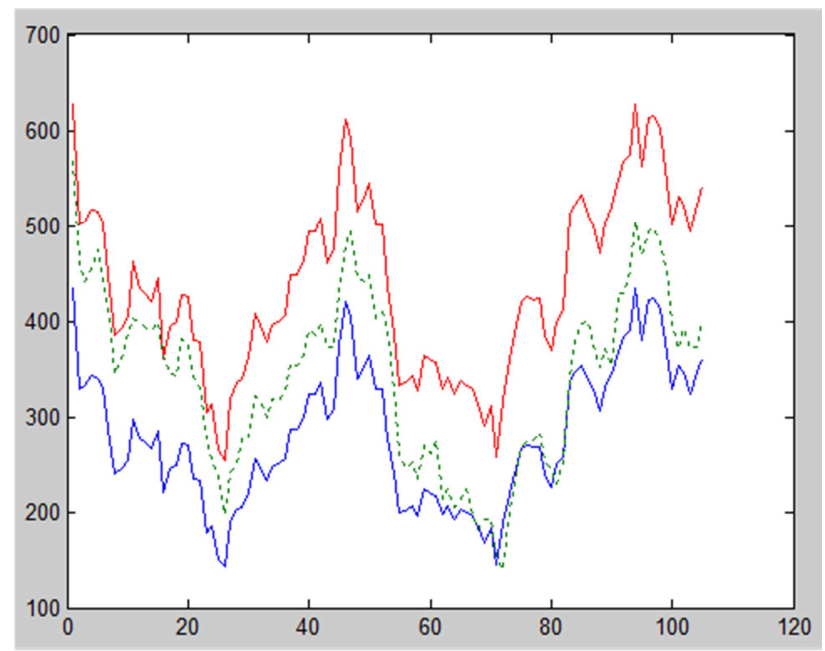

Figure 8. The prediction price range of a white sugar call option under the Knight parameter $\alpha=0.5$.

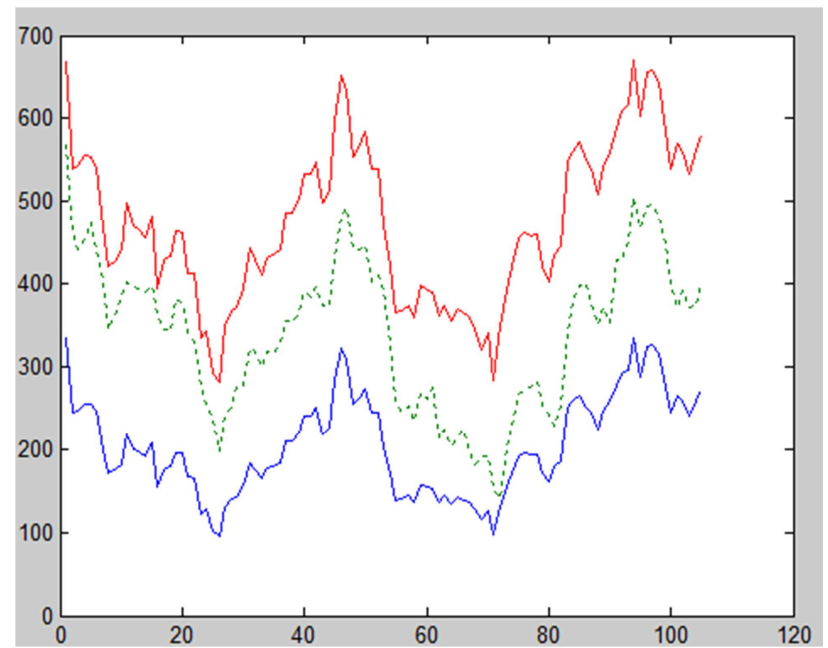

Figure 9. The prediction price range of a white sugar call option under the Knight parameter $\alpha=1$.

It can be seen from the diagram that the model has a better fitting result for the price of white sugar.

And the price range of the call options for white sugar options was gotten under the different degree of net 
uncertainty ( $\alpha=0.05, \alpha=0.1, \alpha=0.5, \alpha=1, \alpha=2, \alpha=3$ ) (Figure 6- Figure11).

These figures show that the forecast results are close to the real price when $\alpha \in[0,1]$, the pricing results will be distorted when the parameters $\alpha$ are higher. It will be more appropriate when $\alpha \in[0,0.5]$ if you want to get closer to the real price.

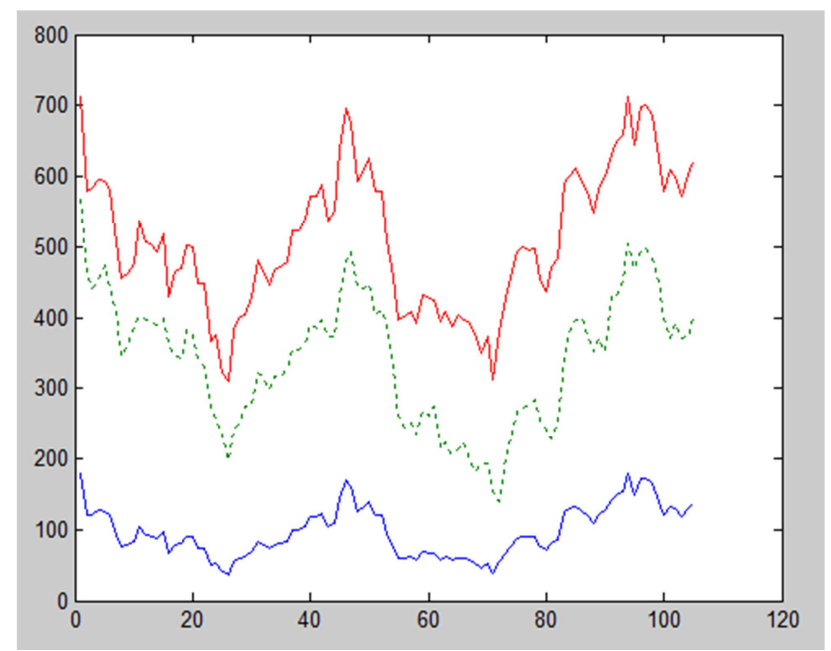

Figure 10. The prediction price range of a white sugar call option under the Knight parameter $\alpha=2$.

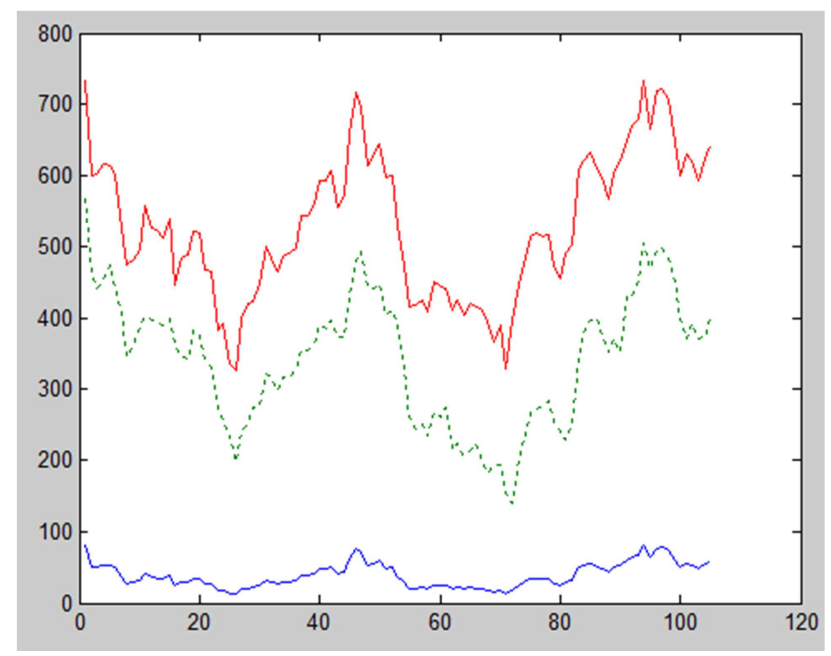

Figure 11. The prediction price range of a white sugar call option under the Knight parameter $\alpha=3$.

The size of the parameter $\alpha$ of Knight Uncertainty has great influence on the lower bounds and has less influence on the upper bound. With the increase of nit uncertainty, the pricing range becomes larger. The lower price bounds will be magnified when $\alpha>1$.

\section{Conclusion}

The relationship between the Knight Uncertainty parameters and the price of financial products is discussed in this paper. The influence of Knight Uncertainty on the pricing of white sugar options is analyzed by model testing through real financial market data. The results show that the model has better applicability. Next, the pricing model can been used to extend the research object to exotic options, such as compound option, jump option, even futures and so on. Therefore, it is necessary to further ponder on the basis of these studies.

\section{Acknowledgements}

This research is financially supported by the scientific research project of The Education Department of Hunan Province, China (Research on Pricing of Financial Derivatives under Knight Uncertainty-17C0820), the Educational Reform Project of Hunan University of Humanities, Science and Technology, China (RKJGY1627), and the construction project about the Out of school practical teaching base (7411602, the practical teaching base of school enterprise cooperation in Finance). All the persons involved in the research projects are thanked for their help.

\section{References}

[1] Knight, Frank. Risk, Uncertainty and Profit [M]. Boston: Houghton Mifflin.

[2] Li Yan Han, Panmin. option pricing based on stochastic volatility under Knightian uncertainty $[\mathrm{J}]$. Systems engineering theory and Practice, 32, 2012, 1175-1183.

[3] Hull J, White A. The pricing of options on assets with stochastic volatilities [J]. Journal of Finance, 42, 1987, 281300 .

[4] Zheng Zhenlong. Financial engineering [M]. Beijing: Higher Education Press, 2016.

[5] John Hull, options, futures and other derivatives [M]. Beijing Tsinghua University press, 2001.

[6] Hua Deng. The measurement model of credit spread and the application analysis based on Zhuji debt [J]. Journal of Hunan University of Arts and Science. 2015, 6: 35-38.

[7] Merton R C. Option pricing when underlying stock returns are discontinuous [J]. Journal of Financial Economics, 3, 1976: 125-144.

[8] Hui Zhang, Xiushan Nie. The minimum pricing model of European stock option under Knight uncertain environment. 2007, 11: 121-126.

[9] Black F, Scholes M. The valuation of option and corporate liabilities [J]. Journal of Political Economy, 81, 1973, 637654 .

[10] Meng Liu. The Pricing of Asset and It's Trading Behavior under the Uncertain Evironment [D]. Master's thesis of Anhui Polytechnic University. 